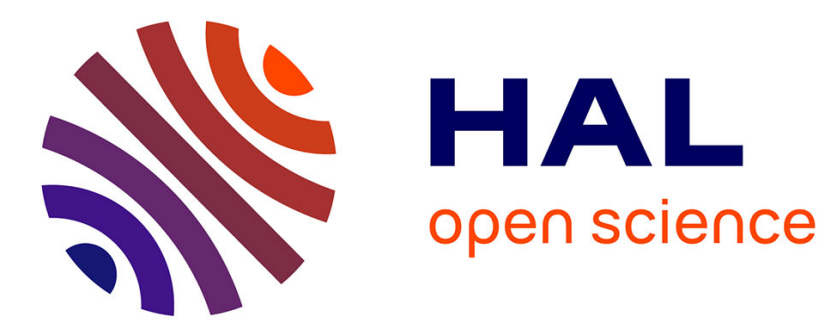

\title{
High-Angle Grain Boundary Migration in Aluminium Bicrystals
}

G. Gottstein, D. Molodov, U. Czubayko, L. Shvindlerman

\section{To cite this version:}

G. Gottstein, D. Molodov, U. Czubayko, L. Shvindlerman. High-Angle Grain Boundary Migration in Aluminium Bicrystals. J. Phys. IV, 1995, 05 (C3), pp.C3-89-C3-106. 10.1051/jp4:1995308 . jpa00253674

\section{HAL Id: jpa-00253674 https://hal.science/jpa-00253674}

Submitted on 1 Jan 1995

HAL is a multi-disciplinary open access archive for the deposit and dissemination of scientific research documents, whether they are published or not. The documents may come from teaching and research institutions in France or abroad, or from public or private research centers.
L'archive ouverte pluridisciplinaire HAL, est destinée au dépôt et à la diffusion de documents scientifiques de niveau recherche, publiés ou non, émanant des établissements d'enseignement et de recherche français ou étrangers, des laboratoires publics ou privés. 


\title{
High-Angle Grain Boundary Migration in Aluminium Bicrystals
}

\author{
G. Gottstein, D.A. Molodov, U. Czubayko, and L.S. Shvindlerman* \\ Institut für Metallkunde und Metallphysik, RWTH Aachen, D-52056 Aachen, Germany \\ * Institute of Solid State Physics, Russian Academy of Science, Chernogolovka, Moscow distr., \\ 142432 Russia
}

\begin{abstract}
The measurement of grain boundary migration in pure $\mathrm{Al}$ bicrystals by $\mathrm{X}$-ray continuous interface tracking is introduced. This method provides information on the mobility of specific grain boundaries without interfering with the process of migration. Moreover, the effect of hydrostatic pressure on grain boundary migration was investigated. Several topics of grain boundary motion relevant to microstructure and texture evolution by recrystallization and grain growth were addressed. It was found that the maximum growth rate misorientation changes with temperature from the exact $\Sigma 7$ orientation relationship to a $40.5^{\circ}<111>$ rotation. This behavior is of concern for recrystallization texture evolution. The effect of material purity on grain boundary migration is shown not to be confined to drag effects but also to involve changes of grain boundary structure. From the activation volume of grain boundary mobility it has to be concluded that at least $<110>$ tilt boundaries move by cooperative motion (group mechanism) of atoms in the boundary.
\end{abstract}

\section{INTRODUCTION}

Recrystallization proceeds by generation and migration of grain boundaries during annealing of deformed structures. Therefore, the migration of grain boundaries is the dominating process of microstructure formation during annealing of cold worked materials. There would be no need to explore the phenomenon of grain boundary motion, if all grain boundaries were alike in their properties, especially in their kinetics. However, the fact that pronounced crystallographic textures are produced during recrystallization, proves that grain boundary properties depend on grain boundary structure, i.e. on its crystallography and chemical composition, which in turn are affected by the state of the material (composition, defects, .....) and processing parameters (temperature, pressure, .....). For microstructure control during recrystallization (and grain growth) it is indispensible to understand the mechanism that control grain boundary kinetics. Such information cannot be retrieved from experiments on polycrystals, since they only yield average properties of the polycrystalline assembly. Therefore, experiments on defined boundaries are needed to elucidate the mechanisms of grain boundary migration. Consequently, we studied the motion of specific grain boundaries in bicrystals. 


\section{EXPERIMENTAL}

The experiments were carried out on bicrystals of high purity Aluminium from both Volhov's Aluminium Plant (VAP), Russia $(99,999 \%)$ and by Vereinigte Aluminium Werke (VAW), Germany $(99,9999 \%)$. The values of the residual resistivity ratio $R_{293 \mathrm{~K}} / \mathrm{R}_{4.2 \mathrm{~K}}$ for these materials were found to be about 17000 and 8000 , respectively.

Grain boundary motion was investigated under a constant driving force $\mathrm{P}$ provided by the surface tension of a curved grain boundary: $P=\sigma a$, where $\sigma$ is the grain boundary surface tension and a the width of the shrinking grain (Fig. 1). The misorientation dependence of grain boundary mobility was studied on pure $<111>$ tilt boundaries with rotation angles in the vicinity of the $\Sigma=7$ misorientation (rotation angle $\varphi=38.2^{\circ}$, Table 1). The pressure dependence of mobility was measured on pure $\langle 100\rangle,\langle 111\rangle$ and $\langle 110\rangle$ tilt grain boundaries. The latter samples were prepared with misorientation angles both close to low $\Sigma$ coincidence relationships (special grain boundaries) with $\Sigma 5\left(36.9^{\circ}<100>\right), \Sigma 7\left(38.2^{\circ}<111>\right.$ ) and $\Sigma 9$ $\left(38.9^{\circ}<110>\right.$ ), and far from coincidence rotations (non-special boundaries) (Table 2 ).

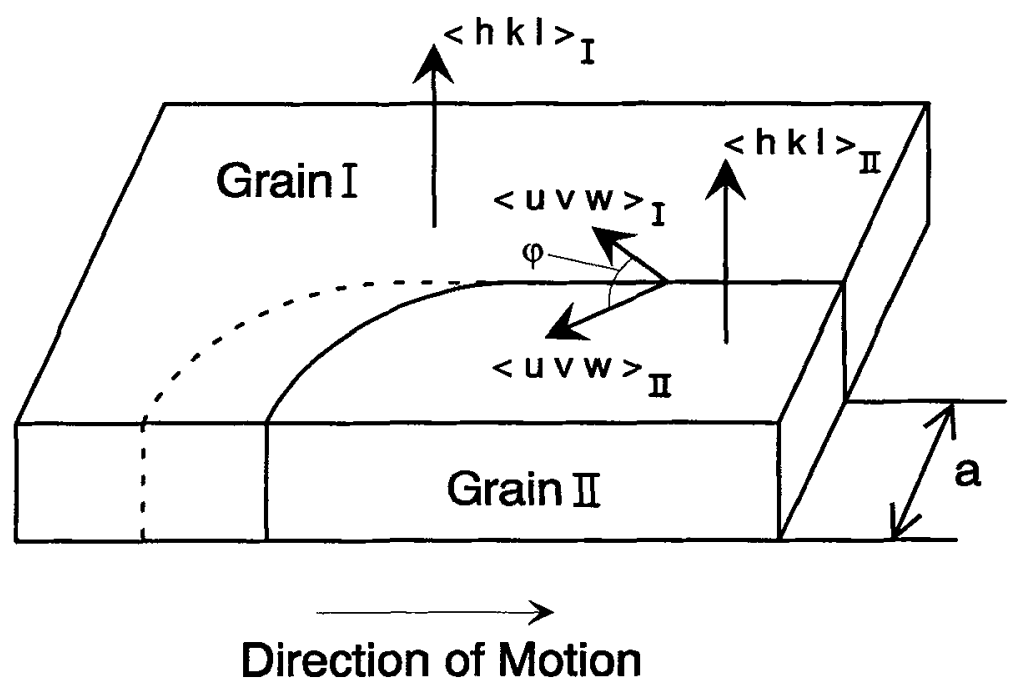

Fig. 1. Used bicrystal geometry for grain boundary motion measurements under a constant driving force. The full line represents the current, the dotted line a prior grain boundary location.

The bicrystals were grown by directional crystallization with the cooling seed in a horizontal mold. The orientation of the crystallographic axes of the monocrystal seeds and the bicrystals was measured by optical means with an absolute accuracy of $\pm 1^{\circ}$, using the characteristic reflection pattern of a laser beam from the specially prepared crystal surface. For this, the samples were etched in a solution of $18 \mathrm{ml} \mathrm{HCl}$, $9 \mathrm{ml} \mathrm{HNO}$ and $2 \mathrm{ml} \mathrm{HF}$. The misorientation of grains in bicrystals were determined with an accuracy of $\pm 0.4^{\circ}$ by measuring the misorientation of etch pits in both grains of the bicrystals under an optical microscope.

To study the characteristics of migration successive high temperature annealings were carried out and the change of grain boundary position with time was recorded. For in-situ tracking of grain boundary motion a specially designed X-ray continuous tracking device0 (XITD) was used. The method of operation is 
Table 1: Misorientation and mobility parameters for the investigated $<111>$ tilt grain boundaries in Al bicrystals.

\begin{tabular}{|ll|ll|ll|}
\hline \multicolumn{2}{|l|}{$\begin{array}{l}\text { Misorientation } \\
\text { Angle }\end{array}$} & \multicolumn{2}{|l|}{$\begin{array}{l}\text { Activation } \\
\text { Enthalpy }\end{array}$} & \multicolumn{2}{|l|}{ Pre-exp. factor } \\
\hline & & $\mathrm{H}[\mathrm{eV}]$ & \multicolumn{2}{|l|}{$\log \left(\mathrm{A}_{0}\left[\mathrm{~m}^{2} / \mathrm{s}\right]\right)$} \\
\hline $35.2^{\circ}$ & $\pm 0.4^{\circ}$ & 2.05 & \pm 0.10 & 6.8 & \pm 0.4 \\
$37.1^{\circ}$ & $\pm 0.4^{\circ}$ & 1.69 & \pm 0.08 & 4.3 & \pm 0.3 \\
$37.4^{\circ}$ & $\pm 0.4^{\circ}$ & 1.32 & \pm 0.07 & 1.5 & \pm 0.1 \\
$37.7^{\circ}$ & $\pm 0.4^{\circ}$ & 1.28 & \pm 0.06 & 1.4 & \pm 0.1 \\
$37.9^{\circ}$ & $\pm 0.4^{\circ}$ & 1.23 & \pm 0.06 & 1.3 & \pm 0.1 \\
$38.2^{\circ}$ & $\pm 0.4^{\circ}$ & 1.29 & \pm 0.06 & 1.6 & \pm 0.1 \\
$38.7^{\circ}$ & $\pm 0.4^{\circ}$ & 1.56 & \pm 0.08 & 3.2 & \pm 0.2 \\
$39.3^{\circ}$ & $\pm 0.4^{\circ}$ & 1.75 & \pm 0.09 & 4.4 & \pm 0.3 \\
$39.9^{\circ}$ & $\pm 0.4^{\circ}$ & 1.80 & \pm 0.09 & 4.8 & \pm 0.3 \\
$40.5^{\circ}$ & $\pm 0.4^{\circ}$ & 2.19 & \pm 0.11 & 8.2 & \pm 0.5 \\
$41.7^{\circ}$ & $\pm 0.4^{\circ}$ & 1.73 & \pm 0.09 & 4.6 & \pm 0.3 \\
$42.5^{\circ}$ & $\pm 0.4^{\circ}$ & 1.56 & \pm 0.08 & 3.4 & \pm 0.2 \\
$43.0^{\circ}$ & $\pm 0.4^{\circ}$ & 1.48 & \pm 0.07 & 2.8 & \pm 0.2 \\
\hline
\end{tabular}

illustrated in Fig. 2. A sample, which contains two differently oriented crystals is mounted such that under the incident X-ray beam one crystal is in Bragg-position while the other is not. A scan of the $X$-ray beam along the sample surface would give an intensity distribution as shown in Fig. 2. The maximum intensity $I_{0}$ is recorded as long as the $\mathrm{X}$-ray spot is entirely located on the surface of crystal I. When crossing the interface between crystals I and II the intensity decreases with decreasing area of the X-ray spot on crystal I. When the $X$-ray spot has completely moved over to crystal II the detected intensity attains the value $I_{u}$. The boundary position can be associated with the position where the intermediate intensity $I_{m}$ is detected. When the boundary moves, the sample is concurrently shifted such that the reflected X-ray intensity remains constant during the measurement. Thus, the velocity of the moving grain boundary is equal to the speed of sample movement at any moment during the experiment.

Table 2: Geometry and activation parameters of migration for investigated grain boundaries in Albicrystals

\begin{tabular}{|c|c|c|c|c|c|}
\hline \multicolumn{3}{|c|}{} & \multicolumn{2}{c|}{} & $\begin{array}{c}\text { Pre-exp. } \\
\text { factor }\end{array}$ \\
\hline Axis & Angle & $\Sigma$ & $\begin{array}{c}\text { Enthalpy H, } \\
{[\mathrm{eV}]}\end{array}$ & $\begin{array}{c}\text { Volume } \\
{\left[\mathrm{V}^{*} / \Omega\right]}\end{array}$ & $\log \left(\mathrm{A}_{\mathrm{o}}\left[\mathrm{m}^{2} / \mathrm{s}\right]\right)$ \\
\hline$<100>$ & $36.9 \pm 0.4$ & 5 & $1.18 \pm 0.06$ & $1.20 \pm 0.06$ & 0.4 \\
\hline$<100>$ & $31.8 \pm 0.4$ & & $1.93 \pm 0.10$ & $1.19 \pm 0.06$ & 6.0 \\
\hline$<111>$ & $37.1 \pm 0.4$ & 7 & $1.67 \pm 0.08$ & $1.10 \pm 0.06$ & 4.3 \\
\hline$<111>$ & $32.0 \pm 0.5$ & & $2.02 \pm 0.10$ & $1.19 \pm 0.06$ & 6.8 \\
\hline$<110>$ & $38.5 \pm 0.5$ & 9 & $1.89 \pm 0.09$ & $1.65 \pm 0.06$ & 3.7 \\
\hline$<110>$ & $36.0 \pm 1.0$ & & $2.31 \pm 0.12$ & $2.22 \pm 0.10$ & 6.3 \\
\hline$<110>$ & $32.0 \pm 1.0$ & & $2.85 \pm 0.14$ & $3.24 \pm 0.17$ & 9.5 \\
\hline$<110>$ & $30.0 \pm 1.0$ & & $3.02 \pm 0.15$ & $3.63 \pm 0.18$ & 10.1 \\
\hline
\end{tabular}

Fig. 3 shows a schematic sketch of the XITD. The computer records the X-ray intensity from the detector and activates the stepping motor of the sample holder such that the recorded intensity remains constant. Because of the size of the X-ray beam the absolute accuracy of locating the grain boundary position is approximately $15 \mu \mathrm{m}$. The device can measure a grain boundary velocity in a wide range between $1 \mu \mathrm{m} / \mathrm{s}$ to $1000 \mu \mathrm{m} / \mathrm{s}$ and allows up to 4 measurements of the boundary position per second. Fig. 4 shows two examples of grain boundary displacement with time during the experiment. The curve in Fig. 4a comprises 429 measuring points. For the high end of boundary velocity the resolution decreases to 2 measuring points per second (Fig. 4b). The velocity is determined by linear regression. Its inaccuracy depends on the frequency of measurements and amounts to $0.5 \%$ (a) and $2.2 \%$ (b), respectively. The hot stage of the device allows a sample temperature between $20^{\circ} \mathrm{C}$ and $1300^{\circ} \mathrm{C}$. During the measurement of grain 


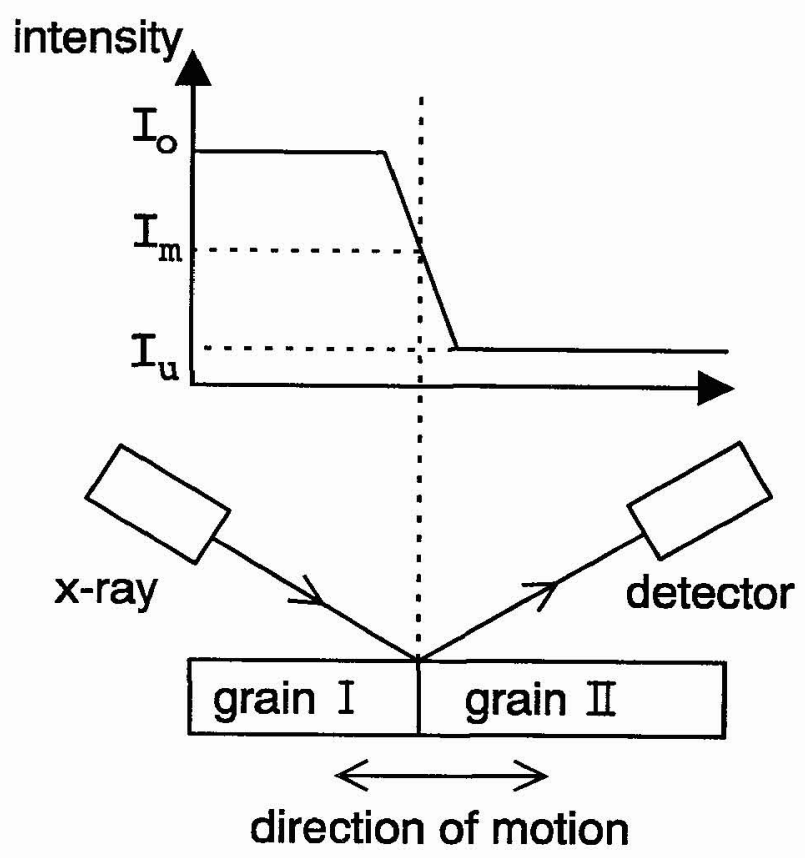

Fig. 2. The change of diffracted X-ray intensity with displacement of the sample with respect to the X-ray spot. Grain $I$ is in the Bragg-setting.

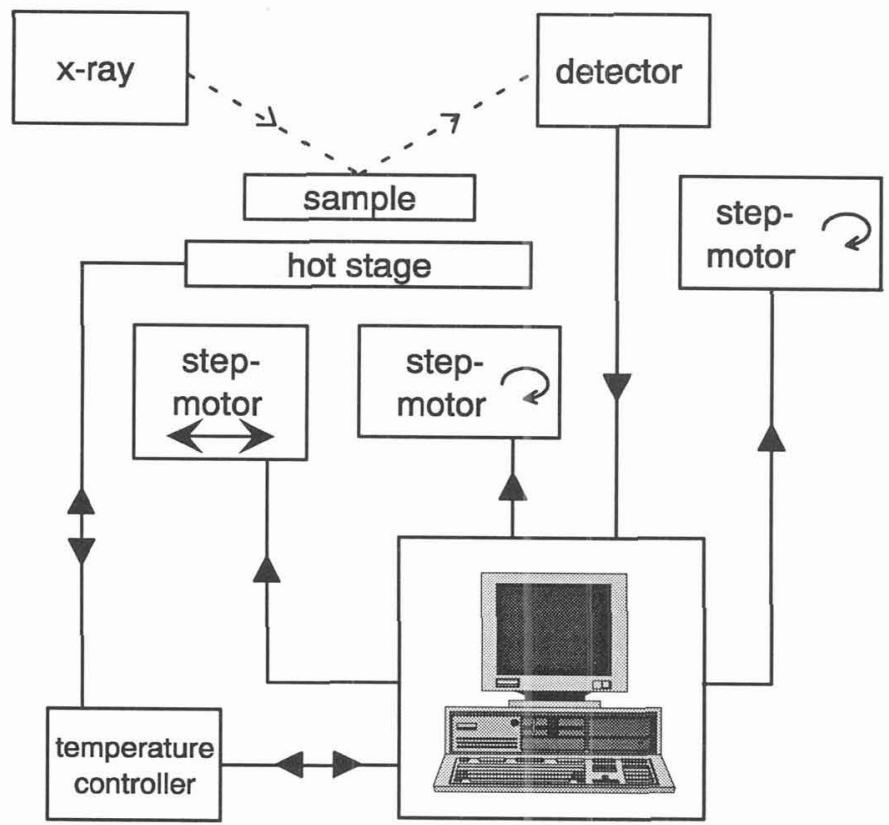

Fig. 3. Block-diagram of the X-ray Interface Tracking Device (XITD). 
a)

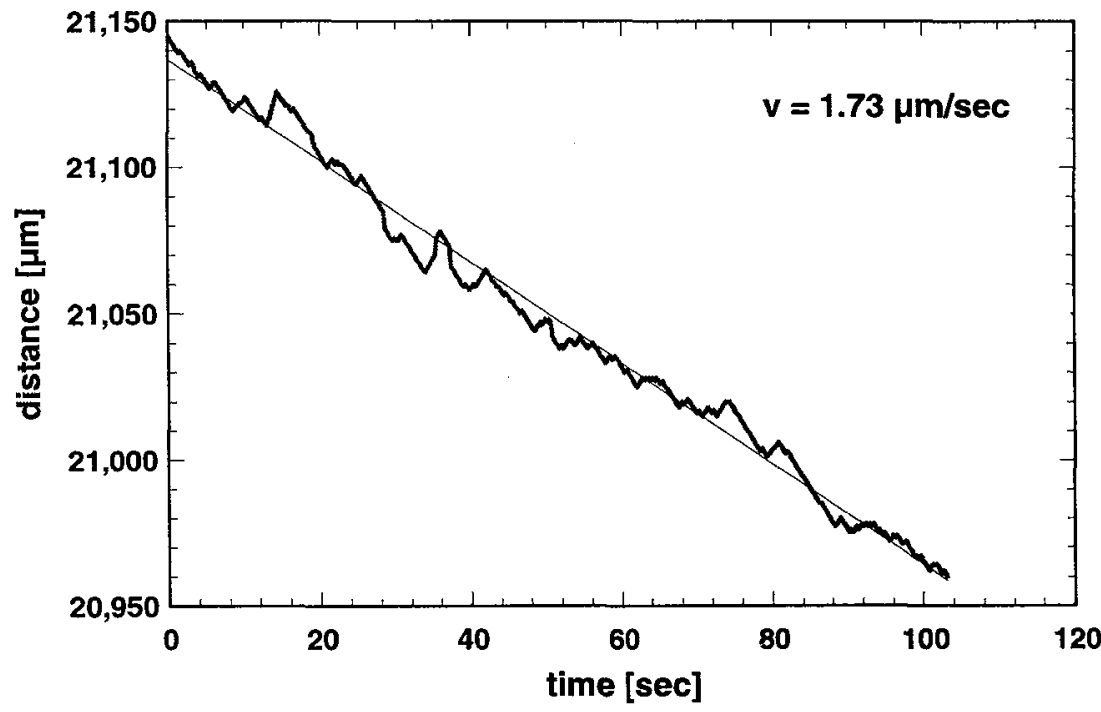

b)

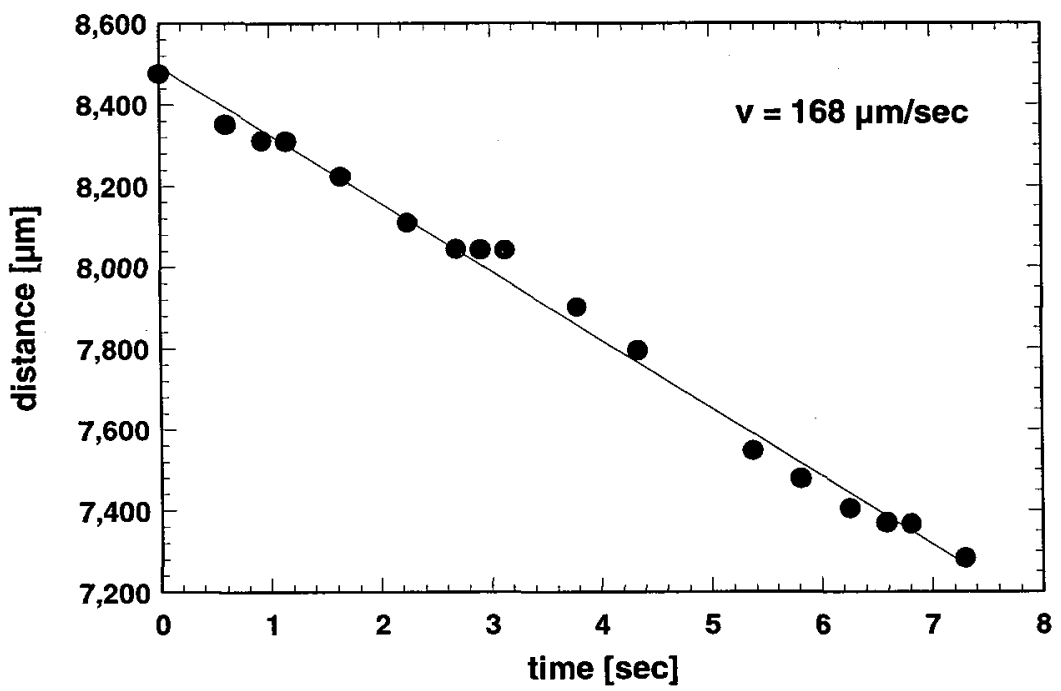

Fig. 4. Distance-time diagrams of grain boundary migration at a) low and b) high velocity.

boundary motion the temperature is kept constant within $\pm 0.3^{\circ}$. To account for thermal expansion of the sample the Bragg-angle is continuously adjusted during temperature changes. To avoid surface oxidation the sample and the hot stage were exposed to a nitrogen gas atmosphere.

The investigations were conducted at both atmospheric pressure and at hydrostatic pressures up to $0.9 \mathrm{GPa}$ in the temperature range between $350-600^{\circ} \mathrm{C}$. The high pressure experiments were conducted in a special 
high temperature chamber. Details of this arrangement are given elsewhere [1]. The temperature of annealing at high pressure was kept constant to within $\pm 1^{\circ} \mathrm{C}$. The position of the moving boundary was determined from grain boundary grooves. Prior to each high pressure annealing the specimen was polished to remove the grooves. The error of the mobility measurement was less than $5 \%$. At high pressures, samples with $\langle 111\rangle$ tilt boundaries were annealed at $425^{\circ} \mathrm{C}$, samples with $\langle 100\rangle$ boundaries at $450^{\circ} \mathrm{C}$ and samples with $<110>$ boundaries at $535^{\circ} \mathrm{C}$ (except samples with $30^{\circ}<111>$ boundaries, which were subjected to annealing at $560^{\circ} \mathrm{C}$ ). The samples were exposed to high pressure by a pressurized argon gas atmosphere. The pressure was kept constant within $\pm 5 \mathrm{MPa}$ in the pressure range up to $0.4 \mathrm{GPa}$ and within $\pm 15 \mathrm{MPa}$ in the pressure range exceeding $0.4 \mathrm{GPa}$.

The mobility of a grain boundary is given by the ratio of velocity $\mathbf{v}$ and driving force $\mathbf{p}$

$$
\mathrm{m}=\frac{\mathrm{v}}{\mathrm{p}}=\frac{\mathrm{v}}{\sigma / \mathrm{a}}
$$

For convenience we use the reduced mobility

$$
A \equiv v a=m \sigma=A_{\circ} \exp \left(-\frac{H}{k T}\right)
$$

where $\mathrm{H}$ is the activation enthalpy of migration and $\mathrm{A}_{\mathrm{O}}$ a pre-exponential factor.

\section{RESULTS}

\subsection{Orientation Dependence of Grain Boundary Motion}

There have been several investigations to prove that grain boundary mobility depends on misorientation across the boundary [2-5]. Aust and Rutter found evidence that low $\Sigma$ coincidence boundaries move faster than random (off-coincidence) boundaries [2]. This was confirmed by detailed investigations of Shvindlerman et al. [3-5] on Al, $\mathrm{Zn}$ and Sn bicrystals, who reported the smallest enthalpy of activation for tilt boundaries between grains of exact coincidence orientation relationship (Fig. 5). As a matter of fact, the highest mobility in $\mathrm{Al}$ was reported for $\Sigma 7$ tilt boundaries.

On the other hand numerous growth selection experiments on $\mathrm{Al}$ single crystals, which were conducted by Lücke, Ibe and coworkers [6-9], provided clear evidence that the maximum growth rate misorientation is close but distinctly different from the exact $\Sigma 7$ orientation relationship, which occurs at an angle of rotation $\varphi=38.2^{\circ}$ (Fig. 6). The angular difference between both results, obtained by very different methods, is comparably small and has been (conveniently) attributed to the large scatter of results in growth selection experiments. However, as already pointed out by Lücke [9], the overwhelming statistics of growth selection experiments substantiate that with progressing growth selection the fastest moving boundaries are observed for $a<111>$ axis of rotation and for an angle $\varphi>40^{\circ}$. Although the difference between growth selection and bicrystal experiments amounts to only $2^{\circ}$, the difference is of prime importance with regard to the interpretation of the misorientation dependence of grain boundary mobility. The finding of a high mobility for low $\Sigma$ coincidence boundaries is commonly interpreted in terms of a decreased tendency to segregation and, therefore, less solute drag in long range periodic boundary structures, like in CSL boundaries, i.e. higher boundary mobility [2]. The finding of a maximum growth rate for off-coincidence (non-special) grain boundaries would be at variance with this interpretation.

To resolve this controversial issue we determined the grain boundary mobility of $\langle 111\rangle$ tilt grain boundaries with angles of rotation $35^{\circ} \leq \varphi \leq 42^{\circ}$ in intervals of $\Delta \varphi=0.4^{\circ}$. Evidently, the activation enthalpy of grain boundary mobility is at maximum for $\varphi=40.5^{\circ}$ and at minimum for the exact $\Sigma 7$ misorientation (Fig. 7). 


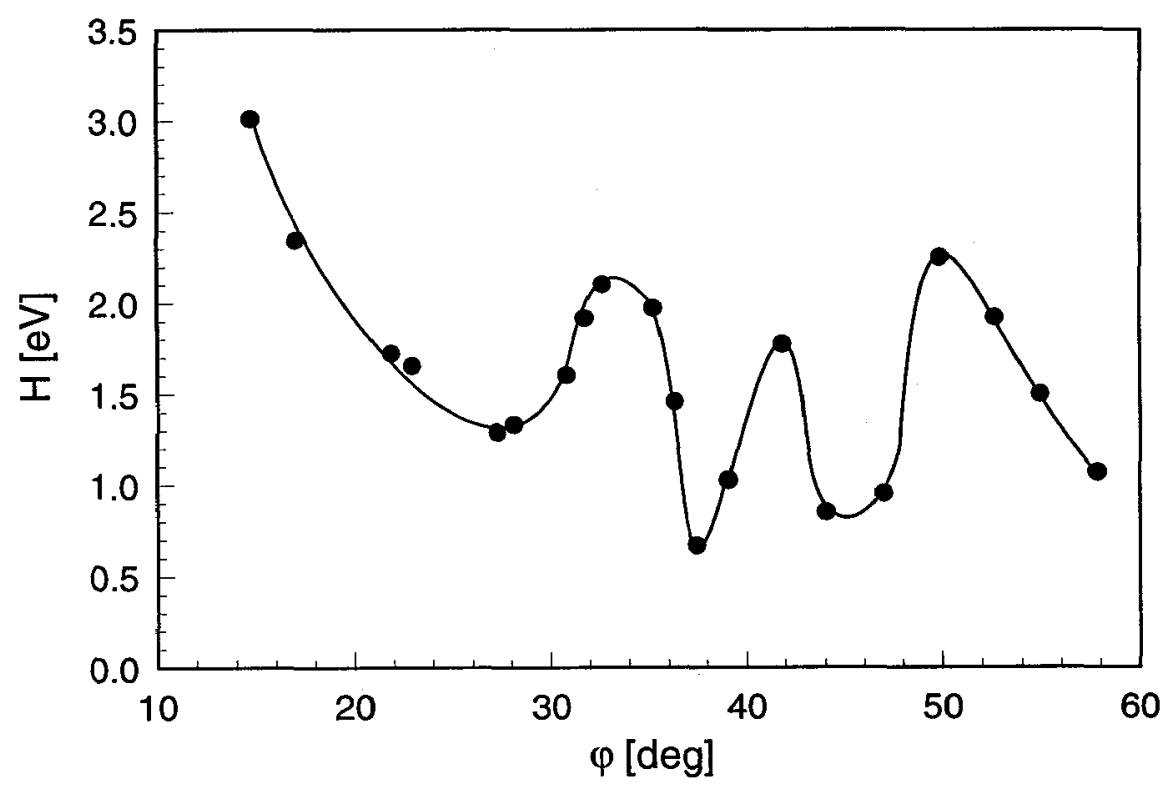

Fig. 5. Misorientation dependence of activation enthalpy for grain boundary motion of $<111>$ tilt grain boundaries in $\mathrm{Al}$ [Aristov, Shvindlerman].

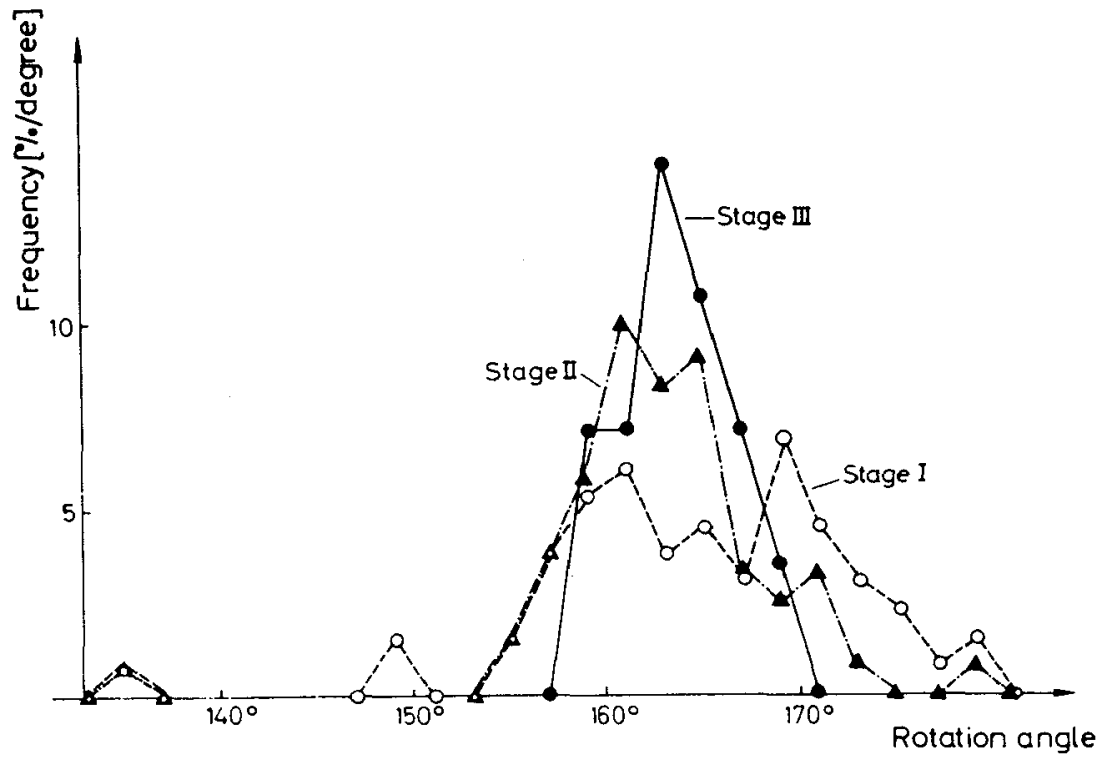

Fig. 6. Growth selection in $20 \%$ rolled aluminium single crystals as observed at three consecutive stages. Frequency of the rotation angles around the best fitting $<111>$ rotation axes [Ibe, Lücke]. 


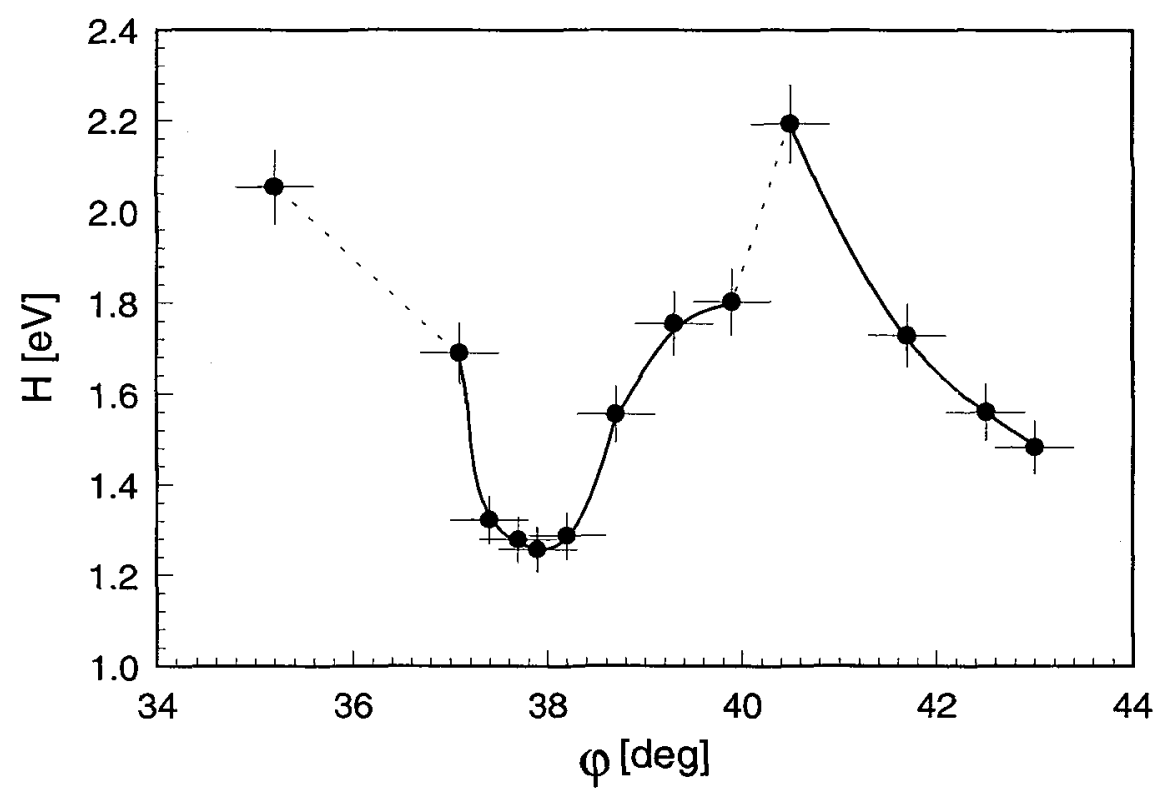

Fig. 7. Misorientation dependence of activation enthalpy for migration of $<111>$ tilt grain boundaries.

However, the mobility

$$
A=A_{0} \exp \left(-\frac{H}{k T}\right)
$$

also depends on the pre-exponential factor $\mathrm{A}_{0}$ which is not constant but again at minimum for the exact $\Sigma 7$ boundary and at maximum for $\varphi=40.5^{\circ}$ (Fig. 8). Therefore, the temperature dependence of grain boundary mobility varies with misorientation and in fact, there is a temperature, the so-called compensation temperature $T_{c}$, where the mobilities of the differently oriented boundaries are the same and, as a result, for $T>T_{c}$, the mobility is higher for grain boundaries with higher activation energy, in particular it is at maximum for $\varphi=40.5^{\circ}$ while for $T<T_{c}$ the exact $\Sigma 7$ boundary moves faster (Fig. 9). This result easily reconciles the seemingly contradictory results of previous bicrystal and growth selection experiments. The main reason for the variance is the different temperature of measurement for the two experimental methods. Growth selection experiments were conducted at very high temperatures, namely above $600^{\circ} \mathrm{C}\left(\approx 615^{\circ} \mathrm{C}\right)$. Extrapolation of the current data to $615^{\circ}$ yield a mobility, which is orders of magnitude higher for the $\left.40.5^{\circ}<111\right\rangle$ boundary compared to all other boundaries (Fig. 10). Recrystallization and conventional bicrystal experiments were usually conducted at $\mathrm{T}<\mathrm{T}_{\mathrm{c}}$ so that the finding of maximum mobility for $38.2^{\circ}<111>$ boundaries can be as well understood from the results of the current study.

The reason for the different maximum growth rate orientation in different temperature regimes is obviously the orientation dependence of both, the activation enthalpy and the pre-exponential factor (Fig. 11). In fact, activation enthalpy and pre-exponential factor are related to each other, namely

$$
H=k T_{c} \ln A_{o}+B
$$




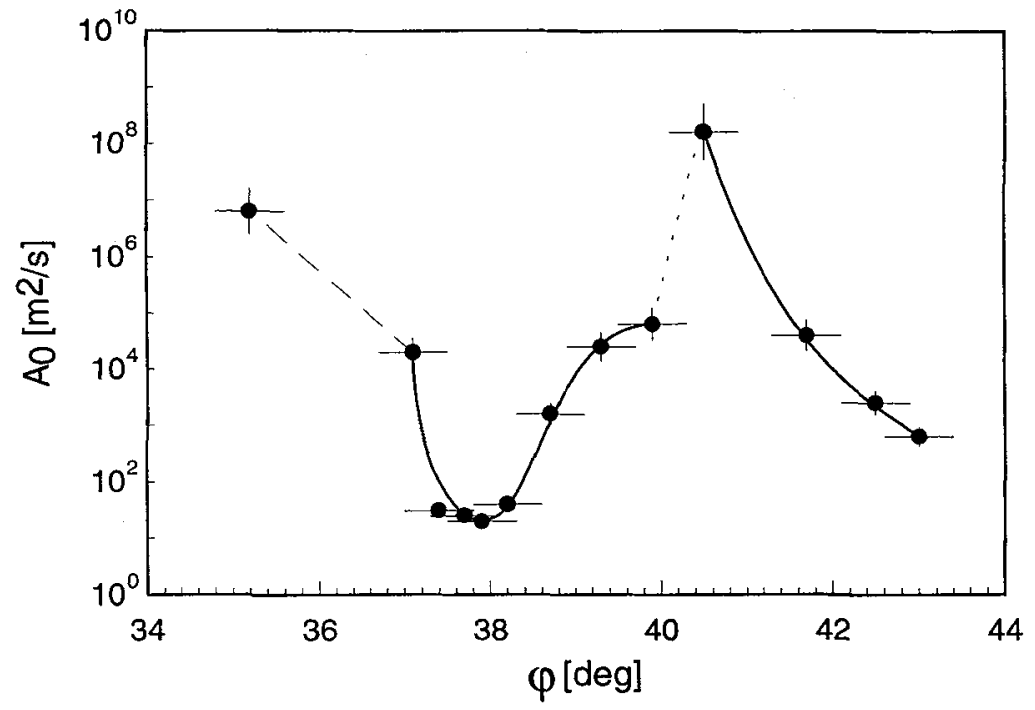

Fig. 8. Misorientation dependence of the pre-exponential mobility factor for $<111>$ tilt grain boundaries.

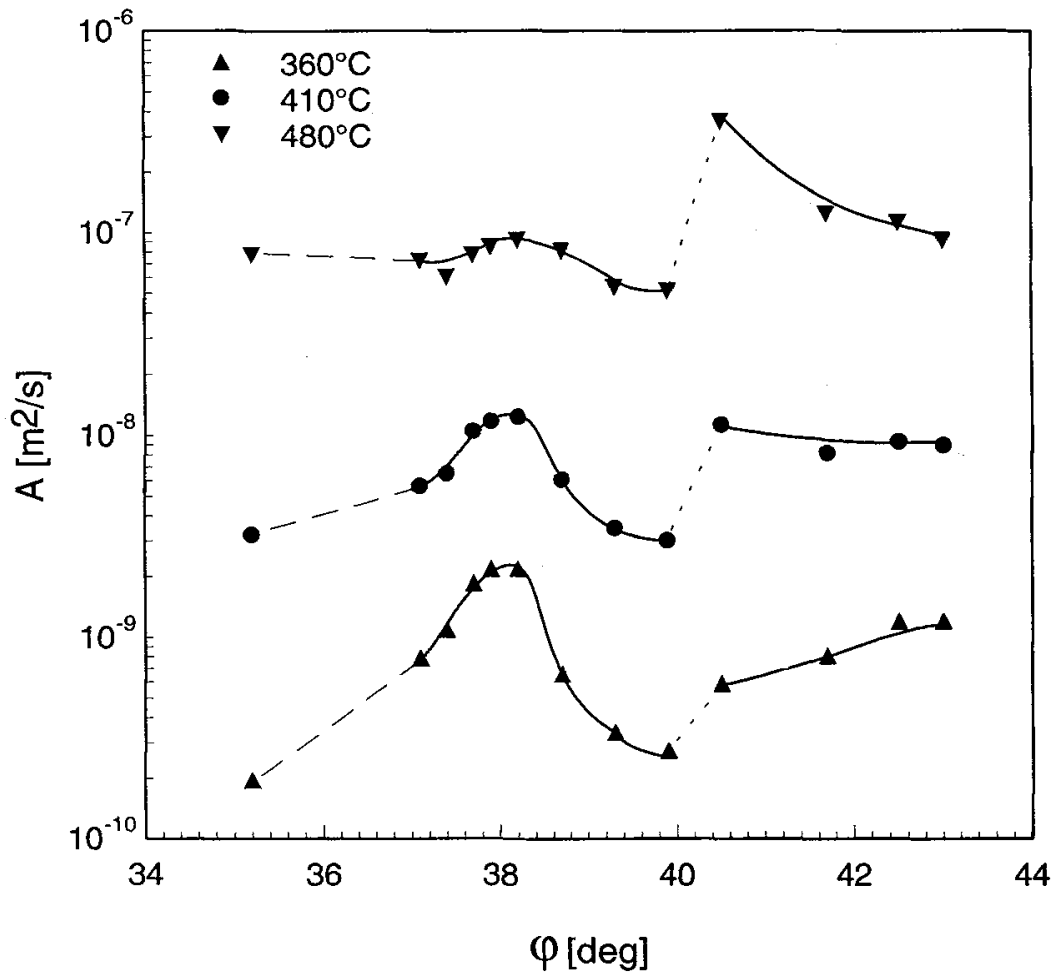

Fig. 9. Misorientation dependence of grain boundary mobility for $<111>$ tilt boundaries in $\mathrm{Al}$ at different temperatures. 


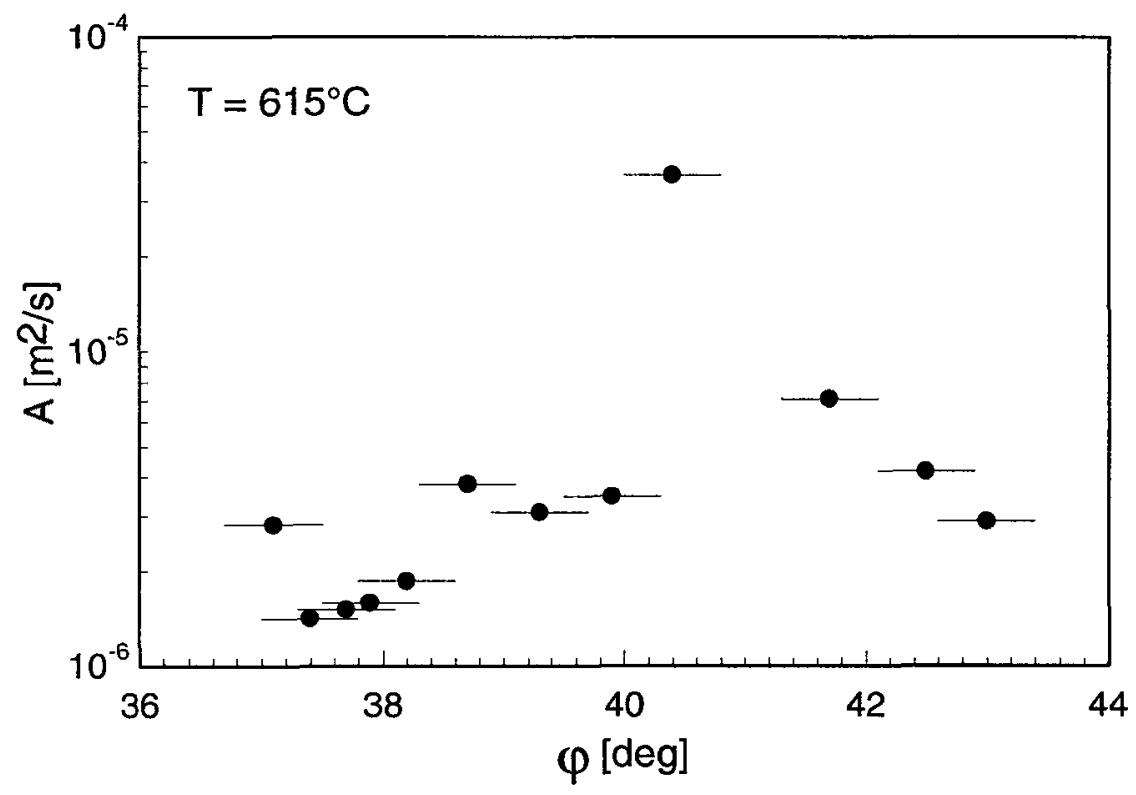

Fig. 10. Mobility of $<111>$ tilt grain boundaries in $\mathrm{Al}$ at $615^{\circ} \mathrm{C}$ (obtained by extrapolation of the measured temperature dependence to $615^{\circ} \mathrm{C}$ )

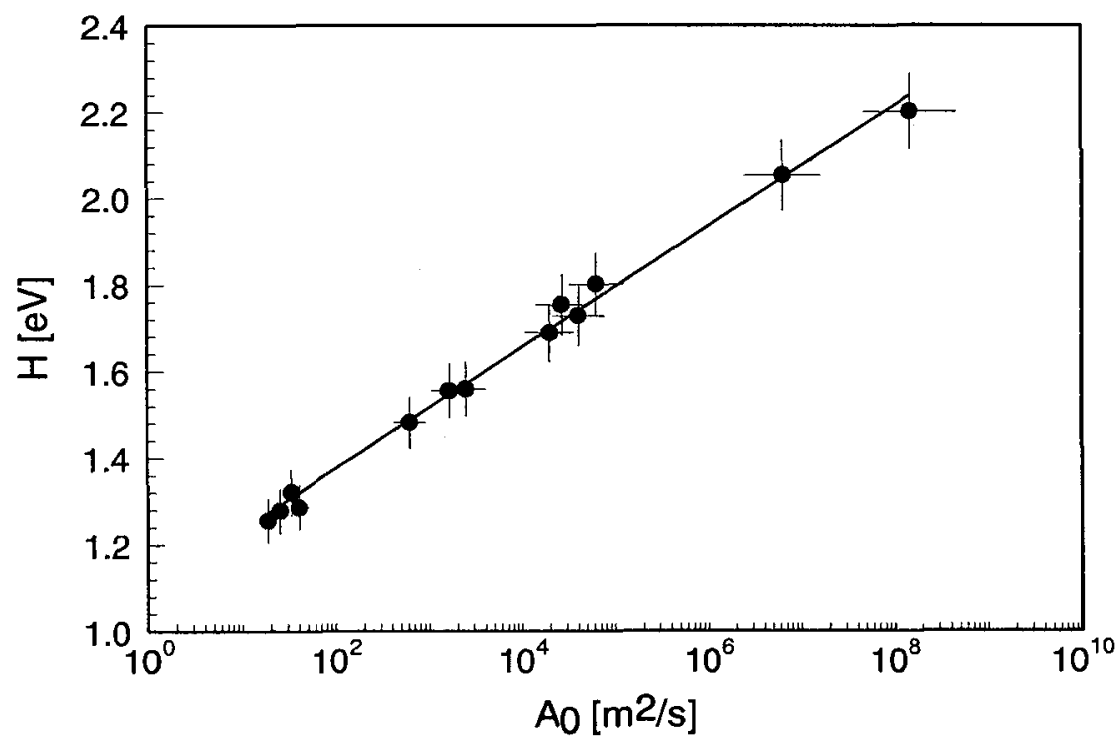

Fig. 11. Dependence of migration activation enthalpy on pre-exponential mobility factor for the investigated $<111>$ tilt grain boundaries. 
where B is a constant. Such dependency is very common in the kinetics of thermally activated interface processes and has fundamental physical reasons, which can be interpreted in terms of a 1st order phase transition from the ground state to the activated state, as can be derived in the framework of irreversible thermodynamics [10]. The relationship requests the existence of a critical temperature (compensation temperature) $T_{c}$, at which the mobilities of the different grain boundaries are equal. According to Fig. 11, $T_{c}=430^{\circ} \mathrm{C}$ for the $\Sigma 7$ boundary. This result emphasizes the importance of the pre-exponential factor (i.e. entropy of activation) for the absolute reaction rate so that caution must be exercised when reaction rates are discussed only in terms of the activation enthalpy.

The effect of a changing maximum growth rate orientation on recrystallization texture development is obviously marginal since the angular difference amounts to only about $2^{\circ}$, but accurate texture analysis ought to be capable of resolving this difference. As an example, both the $38.2^{\circ}<111>$ and the $40.5^{\circ}<111>$ transformation textures of an $\mathrm{Al}$ alloy rolling texture, comprising mainly $S\{123\}<634>, C\{112\}<111>$ and $B\{110\}<112>$ orientation were computed (Fig. 12). The intensity of the rotated Cube orientation ("rotated" about the sheet plane normal in a rolled sample) reveals a noticeable difference of the intensity distribution. It is difficult to resolve this difference from the experimental recrystallization texture, since the nucleation rate of the Cube orientation also plays a role. More detailed investigations on growth selection from a random nucleus specimen are in progress.

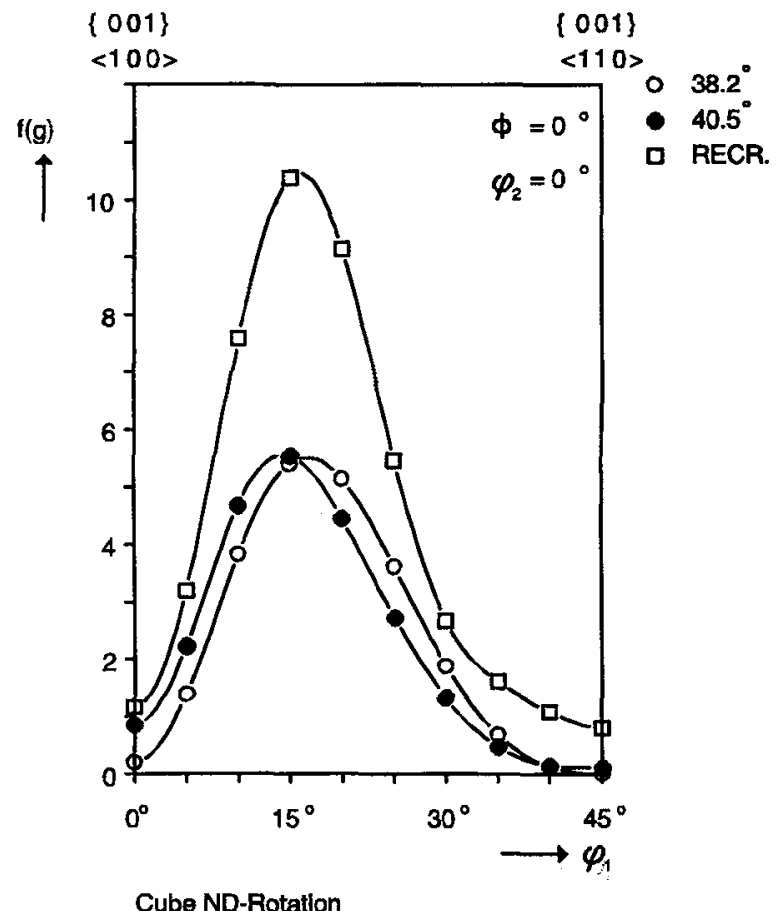

Fig. 12. Orientation density along the $\left(\varphi_{2}=0, \Phi=0\right)$ fiber in Euler space of a two-phase Al-Cu alloy. Transformed deformation texture by $40.5^{\circ}<111>(\odot), 38.2^{\circ}<111>(\mathrm{O})$ and measured recrystallization texture $(\square)$ after annealing at $450^{\circ} \mathrm{C}$. 


\subsection{Effect of Purity}

It is commonly accepted that impurity atoms do affect grain boundary mobility by solute drag. Usually impurity atoms reduce the mobility of grain boundaries, but little is known how much solute drag depends on grain boundary structure, i.e. on misorientation across the boundary. To study this problem, at least for the most dominating grain boundaries in recrystallization, we investigated the orientation dependence of grain boundary mobility in differently pure Al bicrystals for $\langle 111\rangle$ tilt boundaries within the angular interval $37^{\circ} \leq \varphi \leq 43^{\circ}$. Evidently, the mobilities of both materials are different for the same type of boundary, but the difference in activation enthalpy is obviously largest for the exact $\Sigma 7$ boundary and smallest for off coincidence boundaries, in particular $\varphi=40.5^{\circ}$ (Fig. 13). However, the different impurity content has a much deeper consequence, such that the compensation temperature changes (Fig. 14), as obvious from the different slopes of the linear relationship (Fig. 15) according to eq. (4). Such result implies that the change between ground state and activated state differs for (even slightly) differently pure material or, in other words, that the segregated impurity atoms also modify the structure of the grain boundary. This would support the frequent observation that the activation enthalpy of grain boundary motion $\mathrm{H}_{\mathrm{m}}$ can be very high, actually much higher than predicted by impurity drag theory, namely

$$
H_{m} \geq H_{S D}+H_{\text {int }}
$$

where $H_{S D}$ is the activation enthalpy for volume self diffusion and $H_{\text {int }}$ is the interaction enthalpy between grain boundary and impurity atom. Actually, the modification of grain boundary structure may even affect the mechanism of grain boundary motion.

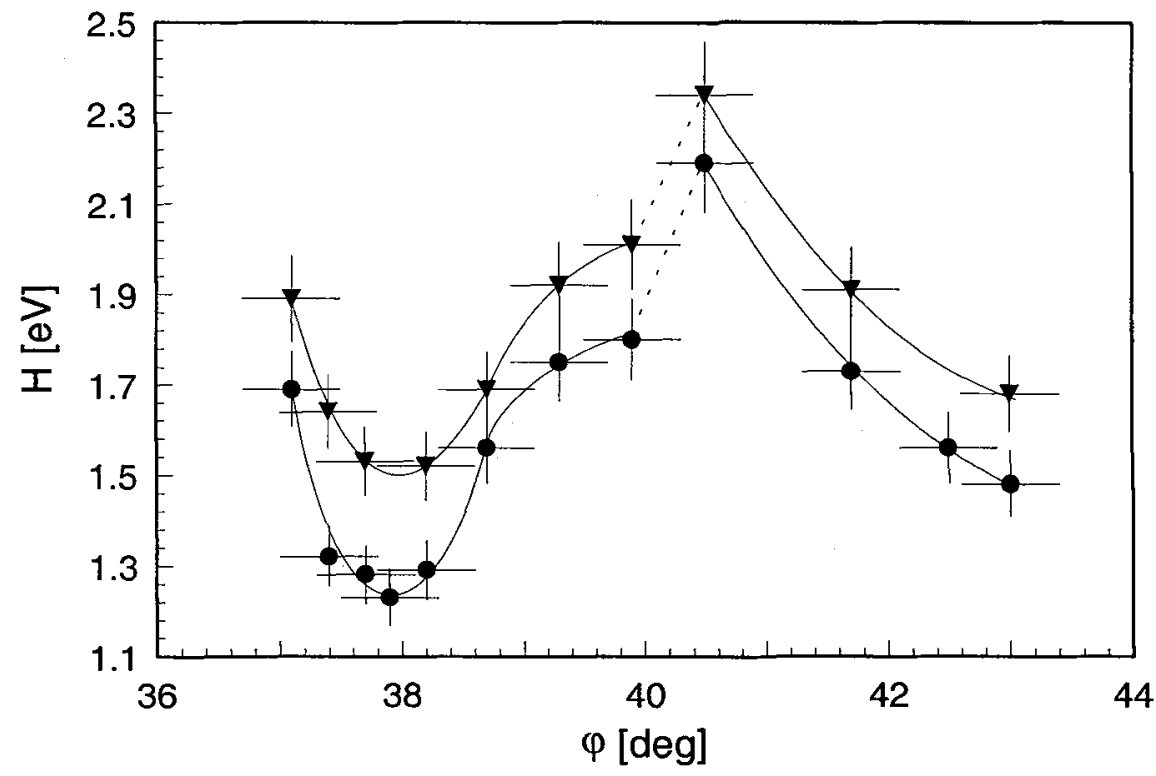

Fig. 13. Activation enthalpy for migration of $<111>$ tilt grain boundaries as a function of misorientation angle for two different aluminium charges: Volhov's Aluminium Plant (Russia); Vereinigte Aluminiumwerke (Germany). 


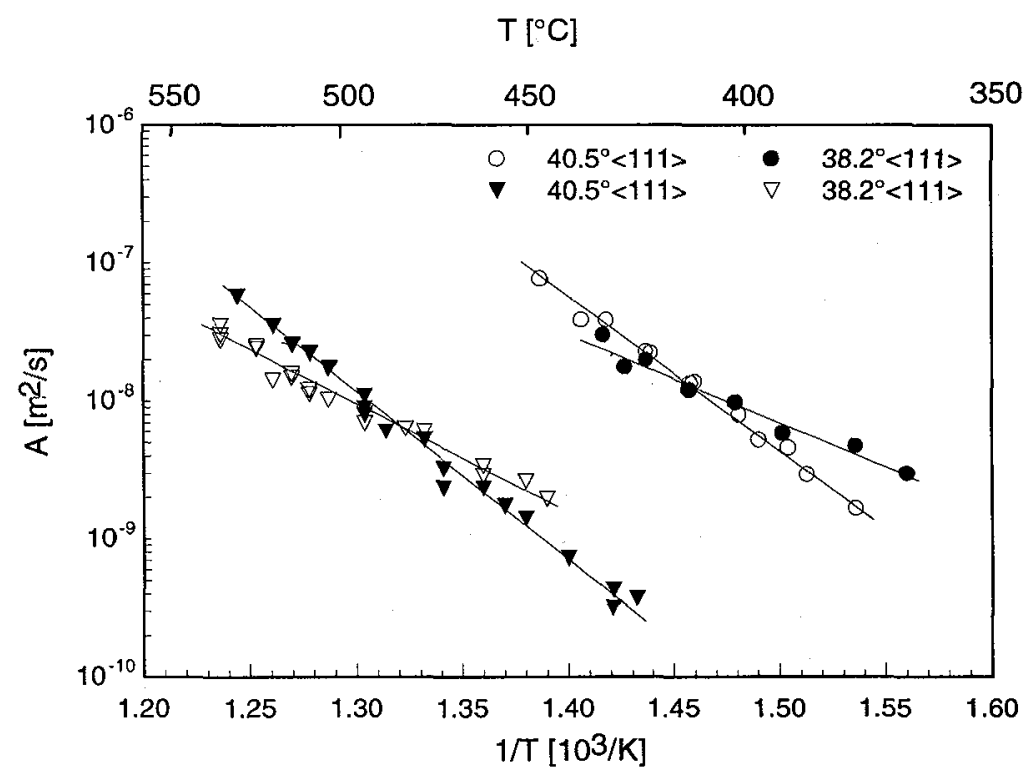

Fig. 14. Temperature dependence of the mobility for $38.2^{\circ}$ and $40.5^{\circ}<111>$ tilt grain boundaries for two different aluminium charges: $O$, VAP (Russia);

$\nabla, \nabla$ VAW (Germany).

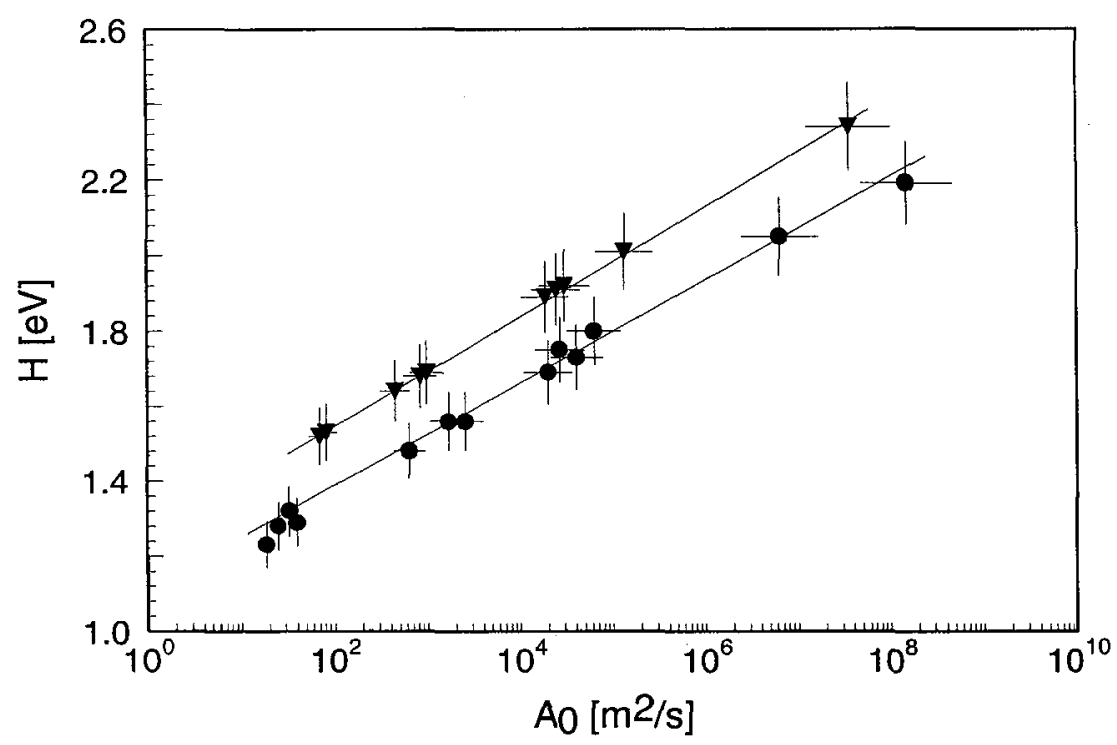

Fig. 15. The dependence of migration activation enthalpy on pre-exponential mobility factor for the investigated $<111>$ tilt grain boundaries in high purity aluminium of two different charges: VAP (Russia); $\nabla$ VAW (Germany). 


\subsection{Activation Volume and Mechanisms of Grain Boundary Motion}

Grain boundary motion consists of the transfer of lattice sites across the grain boundary, which results in the physical displacement of the grain boundary with regard to an external reference frame. (This definition is to differentiate grain boundary motion from diffusion of atoms across the grain boundary without transfer of lattice sites, which would result in the displacement of the grain boundary with respect to the faces of the sample, but not with regard to the laboratory reference frame.) Generally, it is tacitly assumed that the transfer of sites across the boundary is accomplished by the jump of individual atoms through the boundary, possibly complicated by intermediate states $[9,14]$. The displacement of grain boundaries by motion of secondary grain boundary dislocations (SGBDs) is also feasible and has been indeed ovserved $[11,12]$ but the thin film bicrystal experiments by Babcock and Balluffi [11] have clearly disproved that SGBD motion constitutes the intrinsic mechanism of grain boundary migration. In the literature, there have been proposals [13] and speculations [14] of more complicated migration mechanisms involving more than a single lattice site, i.e. cooperative motion of atoms (island model etc.). In fact, Jhan and Bristowe [15] found indications in molecular dynamics computer simulation studies of migration of a $\Sigma 5$ grain boundary that coordinated rearrangement of atoms may occur during grain boundary migration. A. Brokman and S. Ahoron [15] came to the same conclusion. However, no solid experimental proof of cooperative atomic motion as the elementary act of grain boundary migration has been presented so far. Also, the activation enthalpy of grain boundary migration does not provide unambiguous information on the mechanism of grain boundary motion, since a variety of factors, in particular specific electronic components, which are difficult to associate with a particular mechanism without understanding their very nature, contribute to its magnitude.

A thermodynamic quantity that is more directly related to the mechanism of motion is the volume change associated with the activated state of the process, i.e. the activation volume. By definition, the activation volume is the volume difference between the activated state and the ground state. This activation volume can be determined experimentally by measurement of the pressure dependence of grain boundary mobility. According to eq. (2)

$$
A=A_{0} \exp \left(-\frac{H}{k T}\right)=A_{0} \exp \left(-\frac{E+p V^{*}}{k T}\right)
$$

where $\mathrm{E}$ is the activation energy and $\mathrm{V}^{*}$ the activation volume. Accordingly

$$
V^{*}=-\left.k T \frac{\partial \ln A}{\partial p}\right|_{T}
$$

If $\mathrm{V}^{*}$ does not change with pressure, $\mathrm{V}^{*} / \mathrm{kT}$ equals the slope of the straight line in a plot $\ln \mathrm{A}$ vs. $\mathrm{p}$ (Fig. 16). For a $32^{\circ}$ rotation about $\langle 100\rangle,\langle 111\rangle$ and $\langle 110\rangle$ it is apparent that the activation volume for the $<100>$ and $<111>$ boundaries is very similar but different from $<110>$ tilt boundaries. The summary of all measurements (Fig. 17) revealed that the activation volume for the $\langle 100\rangle$ and $\langle 111\rangle$ tilt boundaries was virtually the same for all measured boundaries, including special and non-special boundaries, with a magnitude of about 1.2 atomic volumes. In contrast, the $\langle 110\rangle$ tilt boundaries yielded a higher activation volume and showed a distinct increase of $V^{*}$ with increasing activation enthalpy $\mathrm{H}$. Actually $\mathrm{V}^{*}$ increased up to almost four atomic volumes for $\langle 110\rangle$ tilt boundaries. From this result we have to conclude that at least for $\langle 110\rangle$ tilt boundaries more than a single atom is involved in the activation process of grain boundary migration, i.e. motion proceeds by cooperative motion of atoms (group mechanism). For $\langle 100\rangle$ and $<111>$ tilt boundaries the activation volume is comparable to the activation volume for bulk self diffusion. In this case the experimental results of grain boundary motion would also justify the assumption of a monoatomic jump process. However, a cooperative motion cannot be ruled out even in this case, since the actual activation volume for a site exchange in the boundary depends on the specific site and is not 
well known, but maybe much less than a single atomic volume. Owing to the relationship between activation enthalpy and (log) pre-exponential factor (eq.4), the activation volume depends in a similar way on $\log A_{o}$ as it does on $H$ (Fig. 18).
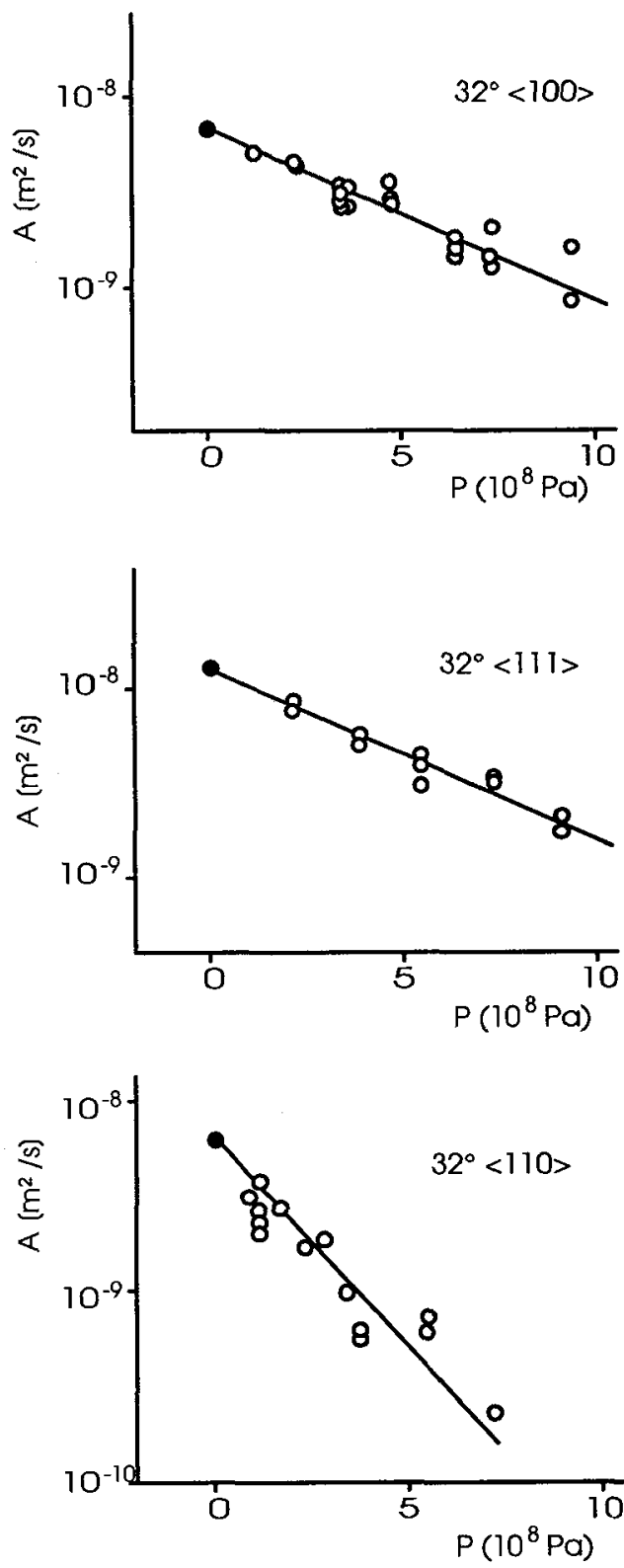

Fig.16. Pressure dependence of grain boundary mobility for tilt grain boundaries with different rotation axes but same angle of misorientation 


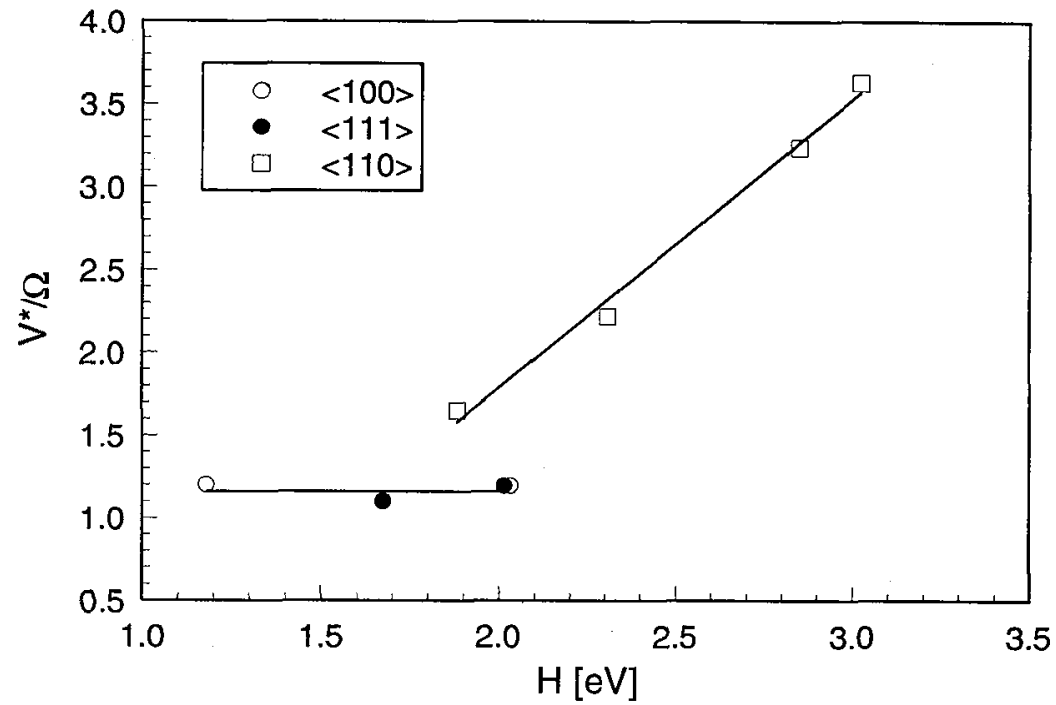

Fig. 17. Activation volume $\mathrm{V}^{*}$ normalized with the atomic volume $\Omega$ as a function of the activation enthalpy $\mathrm{H}$ of tilt grain boundaries with different rotation axes in $\mathrm{Al}$.

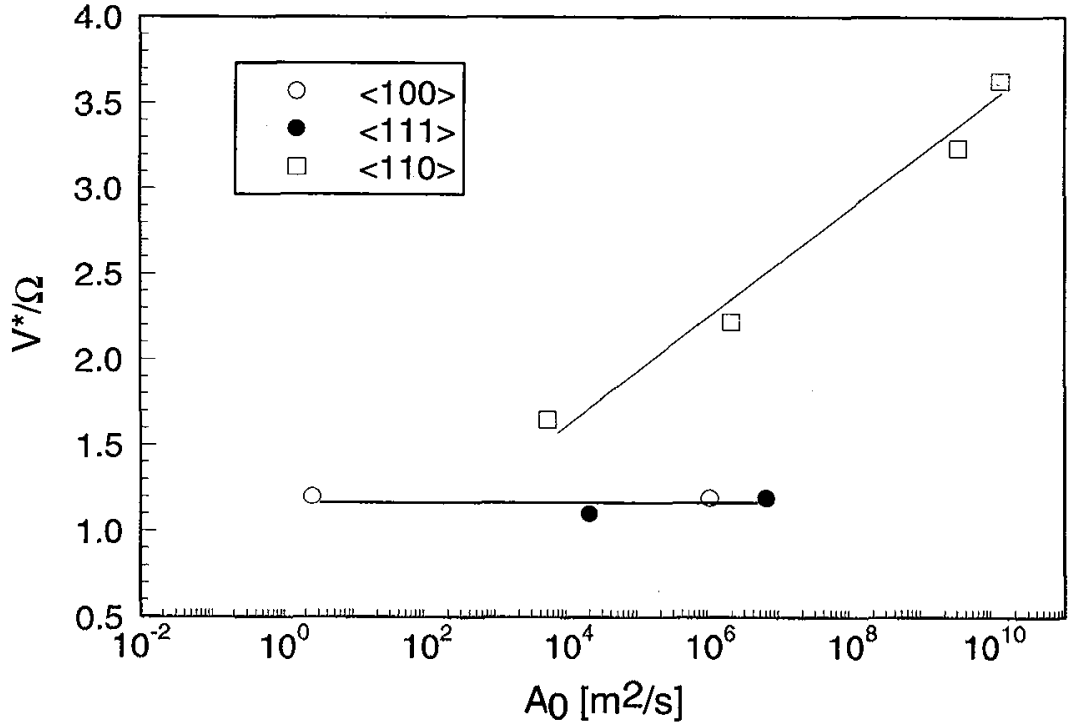

Fig.18. The normalized activation volume $V * / \Omega$ vs. the pre-exponential factor of grain boundary mobility. 


\section{CONCLUSIONS}

An X-Ray Continuous Interface Tracking Device was introduced which allows to track grain boundary motion without interfering with the migration process. The device was utilized to measure the grain boundary mobility of tilt grain boundaries in Aluminium bicrystals. The following results were obtained.

1. The maximum growth rate orientation relationship (MGROR), which determines the texture evolution during recrystallization, depends on the temperature range where the annealing is conducted. At low annealing temperatures $\left(\mathrm{T}<430^{\circ}\right)$ the exact $\Sigma 7\left(38.2^{\circ}<111>\right)$ tilt boundary moves fastest. At higher temperatures $\left(\mathrm{T}>430^{\circ}\right)$ the off-coincidence $40.5^{\circ}<111>$ boundary migrates with highest mobility. This result reconciles previous growth selection and recrystallization experiments. It is due to the so-called compensation effect which relates the entropy of activation to the activation enthalpy. The change of the MGROR with temperature ought to cause a slight but distinct change of recrystallization texture.

2. The impurity drag effect depends on misorientation across the boundary. The change of activation energy with changing purity is largest for low $\Sigma$ coincidence boundaries but less for non-special grain boundaries. The change of the compensation temperature with rising impurity concentration reflects a change of grain boundary structure with composition of the material.

3. The pressure dependence of grain boundary mobility yields the activation volume for grain boundary motion. The results ascertain that $<110>$ tilt boundaries move by cooperative motion of several atoms, while $\langle 100\rangle$ and $\langle 111>$ tilt boundaries have activation volumes which could also be interpreted in terms of a single atomic jump mechanism of grain boundary motion. However, these results do not rule out the possibility of cooperative atomic motion as grain boundary migration mechanism also for $<100>$ and $<111>$ tilt boundaries.

\section{Acknowledgements}

The authors express their gratitude to the Deutsche Forschungsgemeinschaft for financial support of the project. D.A. Molodov would like to thank the Alexander von Humboldt Stiftung for financial support of his stay at the Institut für Metallkunde und Metallphysik, RWTH Aachen. L.S. Shvindlerman gratefully acknowledges the funding of a guest-professorship at the RWTH Aachen by the SEW Eurodrive foundation.

\section{References}

[1] Molodov D.A., Swiderski J., Gottstein G., Lojkowskii W., and Shvindlerman L.S., Acta metall. mater., 42 (1994) 3397.

[2] Rutter J.W. and Aust K.T., Acta metall., 13 (1965) 181.

[3] Aristov V. Yu, Mirochnik V.L., and Shvindlerman L.S., Sov. Phys. Solid State 18 (1976) 137.

[4] Sursaeva L.G., Andreeva A.V., Kopezki Ch. V., and Shvindlerman L.S., Phys. met. metall., 41 (1976) 98 .

[5] Molodov D.A., Straumal B.B., and Shvindlerman L.S., Scripta metall., 18 (1984) 207.

[6] Ibe G., and Lücke K., Recrystallization, Grain Growth and Textures (American Society for Metals, Metals Park, Ohio 1966) pp. 434.

[7] Ibe G., Dietz W., Fraker A.-C., and Lücke K., Z. Metallkde. 6 (1970) 498.

[8] Ibe G., Lücke K., Texture 1 (1972) 87.

[9] Lücke K., Canadian Metallurgical Quarterly 13 (1974) 261.

[10] Gottstein G. and Shvindlerman L.S., to be published

[11] Babcock S.E., and Balluffi R.W., Acta metall. 37 (1989) 2357 and 2367

[12] Hashimoto S, and Baudelet B., Scripta metall. 23 (1989) 1855.

[13] Mott N.F., Proc. Phys. Soc., 60 (1948) 391. 
[14] Haessner F. and Hofmann S., "Recrystallization of Metallic Materials", ed. F. Haessner (Dr. Riederer Verlag GmbH, Stuttgart, 1978) pp. 63-95

[15] Jhan R.S. and Bristowe P.D., Scripta metall. 24 (1990) 1313.

[16] Ahoron S., Brokman A., Acta metall. mater., 39 (1991) 2389. 